\title{
O contexto histórico da implantação do Programa Nacional de Imunização (PNI) e sua importância para o Sistema Único de Saúde (SUS)
}

O contexto histórico da vacinação foi palco de críticas e inúmeras rejeições por parte da nossa sociedade. O PNI (Programa Nacional de Imunização) surge como um instrumento de organização e implementação do calendário vacinal no Brasil, baseando-se no perfil epidemiológico de cada região, com periódica atualização. O objetivo desse estudo é discutir a importância do PNI para a saúde pública e prevenção de doenças. Trata-se de um estudo de revisão bibliográfica do tipo qualitativo, onde foram utilizados artigos com publicações num período de 1993 a 2015, pesquisados nas bases de dados SCIELO, LILACS, e na Biblioteca Virtual de Saúde, bem como nos manuais de normas e procedimentos para vacinação regidos pelo Ministério da Saúde. A partir do material encontrado, foi possível reconhecer os avanços trazidos pelo PNI, tendo a visão ampla de saúde, sendo notável o sucesso das ações de imunização na prática dos serviços de saúde. O PNI desempenha um papel importante na promoção da saúde, melhorando a qualidade de vida de grande parcela da humanidade, se encarregando pela redução da mortalidade infantil e o aumento da expectativa de vida.

Palavras-chave: PNI; Vacina; Imunização; Imunobiológicos; Sala de Vacina.

\section{The historical context of the implementation of the National Immunization Program (NIP) and its importance for the Brazilian Health System (SUS)}

\begin{abstract}
The historical context of vaccination was the scene of criticism and numerous rejections on the part of our society. The PNI (National Immunization Program) emerges as an instrument for organizing and implementing the vaccination calendar in Brazil, based on the epidemiological profile of each region, with a periodical update. The objective of this study is to discuss the importance of the PNI for public health and disease prevention. This is a bibliographic review of the qualitative type, where articles were used with publications from 1993 to 2015, searched in the databases SCIELO, LILACS, and in the Virtual Health Library, as well as in the manuals of norms and procedures for vaccination under the Ministry of Health. From the material found, it was possible to recognize the advances brought by the PNI, having a broad vision of health, being remarkable the success of immunization actions in the practice of health services. The NIP plays an important role in promoting health, improving the quality of life of a large portion of humanity, and in charge of reducing infant mortality and increasing life expectancy.
\end{abstract}

Keywords: PNI; Vaccination; Immunization; Immunobiology; Vaccine Room.

Topic: Enfermagem em Saúde Pública

Reviewed anonymously in the process of blind peer.

Adeânio Almeida Lima

Universidade Federal da Bahia, Brasil

http://lattes.cnpq.br/2437198310313379

adeaniolima@gmail.com

Edenise dos Santos Pinto

Universidade Regional da Bahia, Brasil

http://lattes.cnpq.br/2100964599213353

danielarsouza@outlook.com
Received: 15/05/2017

Approved: 20/07/2017
Referencing this:

LIMA, A. A.; PINTO, E. S.. O contexto histórico da implantação do Programa Nacional de Imunização (PNI) e sua importância para o Sistema Único de Saúde (SUS). Scire Salutis, v.7, n.1, p.53-62, 2017. DOI: http://doi.org/10.6008/SPC2236-9600.2017.001.0005 


\section{INTRODUÇÃO}

A vacinação teve como contexto histórico o momento vivido pela população no século $\mathrm{XIX}$, que enfrentavam o desenfreado poder de vírus como o da varíola, febre amarela e de outras mazelas. Porém, no Brasil, ela ganhou força em meados do século $\mathrm{XX}$, com os graves problemas sanitários que acometiam a população e consequentemente traziam consigo o surgimento de vários problemas de saúde. Inicialmente, as vacinas surgiram como uma forma de minimizar os impactos causados por epidemias avassaladoras. Elas seriam uma medida de controle de doenças de grande impacto nas condições de vida de uma população, funcionando como forma primária de prevenção e erradicação de diferentes patologias.

Amostras de vírus utilizadas para vacinação chegaram ao Brasil em torno de 1840 , trazidas pelo Barão de Barbacena, sendo utilizadas principalmente na proteção de famílias nobres. Posteriormente, o cirurgião Barão de Pedro Afonso, criou um Instituto privado para o preparo de vacina antivariólica no país, sendo mais tarde encarregado pelo governo de estabelecer o Instituto Municipal Soroterápico no Rio de Janeiro, posteriormente, Instituto Oswaldo Cruz (IOC) (SCHATZMAYR, 2001).

Entretanto, as vacinas não foram aceitas de imediato no Brasil, e no ano de 1904, deu início ao movimento caracterizado por "Revolta da Vacina" na capital do Rio de Janeiro, que passava por um quadro caótico sanitário, repercutindo assim em diferentes doenças. Nesse cenário surge uma figura de destaque, o médico e sanitarista Oswaldo Cruz cujo intuito era melhorar as condições dessa cidade com medidas drásticas que impactaram a população, como por exemplo, a obrigatoriedade da vacinação que mesmo sendo de forma positiva foi aplicada maneira autoritária e violenta. Nesse presente ano culminaram com a Revogação da Lei da Vacinação Obrigatória e campanhas de vacinação mais bem sucedidas e coordenadas em todo o mundo, fizeram com que a varíola tenha sido certificada como erradicada em 1973 no Brasil e em 1980 no mundo.

Nesse sentido, surge o PNI (Programa Nacional de Imunização) como um instrumento de organização e implementação do calendário vacinal no Brasil, adotando estratégias que viabiliza e regulamenta a política nacional de humanização baseado na realidade de cada comunidade, ou seja, trata o indivíduo como um ser único que se encontra inserido em sua problemática, ampliando o conceito de saúde. Ao longo dos anos, o calendário de vacina vem sofrendo inúmeras alterações, não só baseada pelo perfil da população, mas também pelo surgimento e gravidade de novas patologias. Inicialmente, o PNI tinha apenas como alvo principal as crianças, porém ao longo dessa trajetória surgiram várias modificações no calendário que hoje abrange todas as faixas etárias, crianças, adolescentes, adultos, gestantes e idosos.

Diante do exposto, busca-se responder a seguinte questão de pesquisa: Como se deu o contexto histórico da implementação do PNI e a sua contribuição para o SUS? O interesse pela temática em estudo emergiu do meu processo de transição profissional do âmbito da saúde hospitalar e curativa para a saúde pública e preventiva, tento como primeiro contato na unidade básica de saúde a prática em sala de vacinação e foi se desenvolvendo durante esse tempo na rede básica. Esse redirecionamento profissional desenhou uma inquietação no que se refere à importância do PNI como forma de organização do calendário vacinal, 
percebendo a necessidade de aprofundamento do tema e conseguinte obter conhecimentos que possam subsidiar ações que fortaleçam o programa, aumentando cada vez mais o número de pessoas imunizadas.

A partir da explanação acima, buscamos como objetivo principal: Discutir a importância do PNI para a saúde pública e prevenção de doenças, atrelando os seguintes objetivos específicos: conhecer aspectos centrais envolvidos na trajetória do PNI; discutir estratégias alocadas às ações de imunização e analisar como o PNI contribui para o controle, eliminação e erradicações das doenças.

\section{REVISÃO TEÓRICA}

\section{Contexto Histórico da Vacina no Mundo}

Mundialmente, a história da vacinação começou no século XIX, onde milhares de pessoas eram acometidas pelo vírus da varíola e outras mazelas. É nesse contexto, que Edward Jenner, médico de origem inglesa, observou que as mulheres responsáveis pela ordenha das vacas contaminados pelos vírus da varíola, muitas das vezes não se contaminavam com a doença, ou apresentavam de maneira não tão agressiva os sintomas da doença. Foi com essa visão intuitiva, que ele percebeu que uma vez em contato com uma patologia, o corpo cria uma série de mecanismos de defesa. Para confirmação de suas ideias, Jenner utilizouse de práticas de inoculação a partir das secreções das pústulas das vacas e inoculou num menino de aproximadamente 8 anos. Inicialmente, o garoto apresentou uma pequena pústula, logo após Edward repetiu a experiência novamente, agora com sucesso, pois o jovem não desenvolveu a doença. Ele não sabia, entretanto, sua experiência seria o passo mais importante para a revolução imunológica no mundo (PLOTKLIN et al., 2008).

No entanto, o termo vacina, só foi criado no ano de 1885 , pelo renomado cientista Louis Pasteur, que no combate aos casos de raiva presente na época, desenvolveu um produto capaz de tornar o organismo humano mais resistente ao vírus da raiva. E a nomenclatura usada para esta substância foi: vacina. Além disso, foi evidente em todo mundo a utilização dessas técnicas para elaboração de outras vacinas compostas por vírus inativados (mortos) ou atenuados (enfraquecidos). As vacinas que vieram após a raiva foram; a contra poliomielite, sarampo, caxumba, rubéola e caxumba, e inúmeras outras que constituem uma gama de imunobiológicos que atualmente imuniza milhões de indivíduos em todo o mundo (BENCHIMOL E TEIXEIRA, 1993).

\section{Contexto Histórico no Brasil}

O contexto histórico da vacina no Brasil ocorreu nos meados do século XX, principalmente na cidade do Rio de Janeiro. Nesta época, os problemas sanitários atingiam a população, levando ao aparecimento de inúmeros problemas de saúde tais como: varíola e febre amarela. Eram constantes as epidemias e morte de centenas de indivíduos. É a partir dessa calamidade que a figura de um médico sanitarista aparece, Oswaldo Crus, foi um médico sanitarista, que se preocupou com a saúde pública do Brasil. Portador de um conhecimento distinto, ele implementou medidas sanitárias na cidade do Rio de Janeiro no intuito de 
combater os constantes surtos que ocorriam. Faziam parte das medidas: a destruiç̧ão de casarões e cortiços no centro da cidade para construção de inúmeras avenidas. Não satisfeita, a população rejeitou tal proposta, uma vez que teriam que abandonar suas residências, e este fato foi a gota d'água para uma das maiores revoluções que ocorreriam no Brasil (PORTO, 2003).

Entretanto, foi no ano de 1904, o ápice da revolta popular. A cidade do Rio de Janeiro foi assolada por uma epidemia de varíola, e para solucionar a questão, Oswaldo Cruz conseguiu através de uma lei, aprovada pelo congresso, que a vacinação contra a varíola fosse obrigatória, pois já havia se instalado um problema de saúde pública. Foram organizadas equipes sanitárias, que tinham ordem judicial para vacinar a força toda população. A sociedade já revoltada com a demolição das casas somada este fato deu início a chamada: Revolta da Vacina, onde os indivíduos resistiam à obrigatoriedade imposta pelo governo e fugiam para os morros. Segundo Souza et al. (2012), a população temia a vacina contra a varíola, pois desconheciam seus efeitos colaterais, além de acreditarem que a mesma era uma maneira dos militares despirem as mulheres da época. Mesmo com tantas discussões e opressão por parte da imprensa, Oswaldo Cruz e sua campanha obtiveram êxito com a erradicação das epidemias de varíola e controle dos mosquitos transmissores da febre amarela.

\section{A Visão Contemporânea da Vacinação e seus Avanços}

Depois de mais de cem anos após a Revolta da Vacina, a visão da sociedade mundial e brasileira mudou em relação à vacinação. O passado de violência e obrigatoriedade, hoje é visto pela população como uma medida eficaz na prevenção de doenças. É relevante afirmar que até hoje as técnicas utilizadas por Edward Jenner e Louis Pasteur são bases na criação de novas vacinas. Os avanços tecnológicos adentraram também ao campo dos imunobiológicos. Exemplo desse fato é o uso da Biotecnologia que compreende os estudos do DNA e células troncos, através do uso do DNA recombinante (combinação de DNAs diferentes), pôde a partir de bactérias e insetos, produzir vacinas, o que antes só era alcançado por meio de soros de pacientes já infectados por doenças. A evolução na produção de inúmeras vacinas é considerada um feito histórico, não é à toa que Plotkin disse: “Com exceção da água potável, nenhuma outra modalidade, nem mesmo antibióticos, teve tanto efeito na redução da mortalidade e crescimento da população como as vacinas (DINIZ et al., 2010)".

\section{O Programa Nacional de Imunização (PNI)}

Em 1973 foi formulado o Programa Nacional de Imunizações (PNI), por determinação do Ministério, com o objetivo de coordenar as ações de imunizações que se caracterizavam, até então, pela descontinuidade, pelo caráter episódico e pela reduzida área de cobertura. A proposta básica para o Programa, constante de documento elaborado por técnicos do Departamento Nacional de Profilaxia e Controle de Doenças (Ministério da Saúde) e da Central de Medicamentos (CEME - Presidência da República), foi aprovada em reunião realizada em Brasília, em 18 de setembro de 1973, presidida pelo próprio Ministro Mário Machado Lemos e contou com a participação de renomados sanitaristas e infectologistas, bem como 
de representantes de diversas instituições. Em 1975 foi institucionalizado o PNI, resultante do somatório de fatores, de âmbito nacional e internacional, que convergiam para estimular e expandir a utilização de agentes imunizantes, buscando a integridade das ações de imunizações realizadas no país. O PNI passou a coordenar, assim, as atividades de imunizações desenvolvidas rotineiramente na rede de serviços e, para tanto, traçou diretrizes pautadas na experiência da Fundação de Serviços de Saúde Pública (FSESP), com a prestação de serviços integrais de saúde através de sua rede própria. A legislação específica sobre imunizações e vigilância epidemiológica (Lei 6.259 de 30 de outubro de 1975 e pelo Decreto $\mathrm{n}^{\circ} 78.231$ de 12 de agosto de 1976) deu ênfase às atividades permanentes de vacinação e contribuiu para fortalecer institucionalmente o Programa (BRASIL, 2015).

\section{METODOLOGIA}

O presente estudo foi realizado a partir de artigos publicados no período de 1993 a 2015, pesquisados nas bases de dados SCIELO, LILACS, e na Biblioteca Virtual de Saúde, bem como nos manuais de normas e procedimentos para vacinação regidos pelo Ministério da Saúde. A seleção dos artigos utilizados na pesquisa envolveu os seguintes critérios de inclusão: artigos em língua portuguesa e inglesa que estivessem disponíveis em texto completo, relevante para o tema discutido e que se adequassem aos seguintes descritores: PNI, vacina, imunização, imunobiológicos, sala de vacina. Foram encontrados cerca de 370 artigos que abordavam o tema em questão. A análise dos dados foi realizada mediante a leitura sistemática e posterior seleção de informações obtidas nos periódicos, incorporados ao estudo de acordo com o tema e objetivos da pesquisa. O critério de exclusão se utilizou da mesma didática, onde foram excluídos os artigos que abordavam de forma superficial, ou não tratavam de fato do tema em questão. Assim, este trabalho utilizou 35 dos 70 artigos inicialmente encontrados para discorrer sobre o tema.

\section{DISCUSSÃO}

\section{A trajetória do PNI}

A história das políticas públicas foi palco de críticas e inúmeras rejeições por parte da nossa sociedade, em especial no surgimento em que determinados surtos e epidemias apareciam. Isso gerava para a população sentimentos distintos já que na sua grande maioria as medidas de controle das doenças eram de coerção e obrigatórias instituídas por leis. O surgimento das vacinas não foi diferente, vários fatos marcam esse contexto histórico que serão descritos no decorrer do estudo (PINTO, 2004).

O ponto negativo no processo histórico de formação do programa e de maior destaque na época foi a da obrigatoriedade da vacinação em combate a varíola, que apesar de ser resolutiva foi conduzida de arbitrária, sem que a população tivesse o menor conhecimento e esclarecimento do que fosse essa ação, causando assim indignação popular e contrária às determinadas ações, na qual se gerou uma série de conflitos drásticos que marcou a história da vacina naquele século (RIO DE JANEIRO, 2006). 
Como forma construtiva, foi criado, o PNI no ano de 1973, como tentativa da eliminação de doenças que acometiam a população brasileira, seguindo o êxito da erradicação da varíola, o seu objetivo é conduzir estratégias de prevenção e/ou controle da incidência de doenças infectocontagiosas, traz como meta vacinar todos os brasileiros em todas as fases da sua vida. No tocante a população idosa que, desde o surgimento da vacina contra a influenza apresentou redução significativa da morbimortalidade e das hospitalizações por doenças respiratórias, que antes eram uma das principais causas de morte nessa faixa etária. É notória a diminuição desse quadro, gerando aumento da expectativa de vida nessa idade (GRAZIELE, 2010).

Outro ponto em questão que merece destaque é o calendário de vacinação, que em seu início era composto apenas contra sete doenças, e foi se expandindo gradativamente. Essa expansão seu deu graças à redução dos quadros de morbimortalidades das doenças que acometiam a população daquela época e hoje na atualidade temos o cartão de vacina da criança, do adolescente, da gestante, do adulto e do idoso (BRASIL, 2009).

$\mathrm{Na}$ atualidade, um dos recentes avanços do programa de imunização foi à criação do SI-PNI, que se refere a um sistema de informação do PNI, desenvolvido para possibilitar, aos gestores envolvidos uma avaliação dinâmica do programa. Como afirmam Boing et al. (2007) à importância do PNI é essencial e contribui de forma decisiva para a saúde pública do Brasil, funcionando como uma estratégia de organização e sistematização do calendário de vacinação ampliando a oferta de vacinas de forma gratuita e igualitária fortalecendo assim os princípios do SUS no processo de promoção e prevenção à saúde da sociedade.

\section{O PNI NA prática do SUS para as unidades de saúde}

Para uma organização adquirir êxito necessita desempenhar atividades como planejamento, organização, direção e controle de suas operações, bem como, estabelecer planos e diretrizes, avaliar resultados e desempenho, controlando as atividades em busca dos objetivos. Nesse presente ponto do estudo é imprescindível comentar sobre a diversidade das práticas do PNI e com isso se faz necessário trazer alguns pontos como: o processo da rede de frio, a rotina da sala de vacinação e as funções básicas, salientando ainda sobre as campanhas desenvolvidas e a importância do ACS na ESF com ênfase na vacinação.

\section{Rede de frio}

De acordo com o Manual de rede de frio proposto pelo Ministério da Saúde (BRASIL, 2013), é relevante entender que a Rede de frio é um processo complexo e que envolve uma série de etapas, para que sua execução não seja comprometida. Seus objetivos estão focados na seguridade dos imubiológicos, uma vez que estes são poucos resistentes às variações de temperaturas, fator que altera sua composição e as inativam. Segundo o ministério da saúde, há elementos básicos que devem compor esta rede para que sua estabilidade seja assegurada. Estes elementos são: níveis de armazenamento e distribuição, equipamentos, cuidados e manipulação por parte da equipe. $\mathrm{O}$ armazenamento das vacinas segue do nível nacional a rede municipal de distribuição. 


\section{Equipamentos da rede de frio e cuidados associados}

Os equipamentos onde são armazenadas as vacinas vão desde geladeiras às câmaras frias. As câmeras são desenvolvidas e projetadas para o armazenamento dos imunobiológicos em grandes quantidades. Eles devem ser armazenados seguindo as orientações e recomendações protocoladas pelo Ministério da Saúde como: colocar o nome do imunobiológico e separá-lo por ordem alfabética, numerar os lotes, identificar o laboratório produtor e sua validade. Nas geladeiras domésticas, além dos cuidados citados anteriormente, deve-se observar os valores adequados da temperatura que serão ideais para manutenção das vacinas. Em consonância as medidas, estão os cuidados na organização interna dos refrigeradores que são realizadas pelos profissionais de enfermagem treinados e capacitados para a manipulação. Os cuidados tomados são: tempo de abertura da porta da geladeira e anotação em impressos dos valores diários registrados, tanto pela manhã, quanto na tarde. Outra questão envolve a organização das vacinas em prateleiras de acordo com as temperaturas suportadas. Na primeira devem ser armazenadas as vacinas que suportem temperaturas negativas, como exemplo: Febre Amarela, Tríplice viral e Tetra viral, e na segunda é usada para armazenar imunobiológicos como: DT, DTP, DTPa, Hepatite B, Influenza, Poliomielite Inativada, Pneumocócica, Meningocócica etc., que não suportam temperaturas baixas. Na parte inferior usa-se garrafas contendo água e corante, sua função é a oferta de baixas temperaturas nos casos de problemas do refrigerador (BRASIL, 2001).

\section{Rotina na sala de vacinação e funções da equipe}

A rotina da vacinação começa a partir da anotação da primeira temperatura do dia. Em seguida é realizada a preparação da caixa térmica, com uso de gelox, aguardando o alcance da temperatura ideal para o depósito dos imunobiológicos. Nesse contexto, atua os profissionais técnicos de enfermagem, responsáveis pela manipulação e administração das vacinas sob supervisão do profissional enfermeiro. É dever da equipe esclarecer e orientar de maneira clara aos pacientes e usuários do serviço. As orientações estão voltadas às funções e reações de cada vacina, preenchimento do cartão vacinal, seguindo as doses mensais em crianças, adultos e gestantes. Além disso, é relevante entender que inúmeras implementações tecnológicas compõem hoje o PNI, o que torna a rotina mais fácil e mais prática. Dados são gerados e encaminhados diariamente para as centrais de vigilância em saúde através de sistemas informatizados (PEREIRA et al., 2009).

\section{Campanhas de vacina}

O Brasil é considerado um dos países que possuem o maior calendário vacinal do mundo. Além desse fato, anualmente são realizadas campanhas de vacinação específicas para algumas doenças como: influenza, poliomielite e mais recentemente contra o HPV, que já se encontra estabelecida no calendário vacinal da adolescente. Os objetivos dessas imunizações específicas é controlar e complementar a prevenção de uma doença em foco. Nesse sentido, metas são almejadas através da vacinação de grupos de riscos como: idosos, crianças e gestantes, pois são mais vulneráveis às algumas patologias. O foco destas metas é uma proteção 
coletiva dos indivíduos já citados, e garantir a quebra da cadeia de transmissão das doenças. O período de realização das campanhas é de geralmente 30 dias, podendo ser prolongados de acordo com a meta a ser batida pelo ministério da saúde (BRASIL, 2001).

\section{Relação dos ACS com a vacinação}

A relação entre os agentes comunitários de saúde no processo de vacinação nas unidades de saúde da família é fundamental, uma vez que são eles a ponte que interliga a comunidade ao atendimento vacinal na unidade. O papel dos ACS vai além de simples orientações às mães e pais. Consiste na elaboração de um trabalho voltado à promoção realizado a partir do contato cotidiano com a população. No entanto, para que esta ação seja eficaz, faz-se necessário um conhecimento básico acerca das funções e objetivos das vacinas, pois muitos são questionados sobre reações dos imunobiológicos e relevância para o bem-estar geral de toda a população (NETO, 2013).

\section{Contribuições do PNI para controle, eliminação e erradicações das doenças}

De acordo com Gonçalves e Machado (2008), podemos afirmar que o programa contribui como uma forma de uma melhor avaliação da dinâmica do calendário de vacinação de todas as faixas etárias, e que as vacinas são consideradas como um dos maiores progressos na área da medicina, por ter sido a responsável direta pelo controle, eliminação e erradicação das inúmeras doenças que acometiam a população mundial e brasileira, pactuando a vacinação de rotina, os dias de vacinação nacionais, as campanhas periódicas e a vigilância epidemiológica, desempenhando um papel importante na promoção da saúde, melhorando a qualidade de vida de grande parcela da humanidade, se encarregando pela redução da mortalidade infantil e o aumento da expectativa de vida.

\section{CONCLUSÕES}

Mediante as exposições realizadas durante o estudo, podemos constatar que o PNI contribuiu positivamente para o fortalecimento do Sistema Único de Saúde através de ações que nortearam e organizaram o calendário de vacina, levando em consideração o quantitativo populacional, faixa etária e área geográfica, aumentando assim a eficácia do programa.

É muito importante que as equipes de todos os serviços e os funcionários que desempenham papéis relacionados ao processo de imunização, estejam envolvidos e comprometidos com o processo de vacinação, na qual se fazendo- se necessário a capacitação constante desses profissionais conforme as normas dos manuais expedidos pelo Ministério da Saúde, bem como de órgãos competentes para que assim ocorra a excelência dos imunobiológicos e a integralidade da assistência aos usuários do serviço.

No contexto das imunizações a enfermagem tem papel primordial em todas as ações de execução do Programa Nacional de Imunizações, desde sua implantação na atenção primária, como também a manutenção e administração das rotinas da sala de vacinação, sendo de responsabilidade do profissional enfermeiro, por meio do seu conhecimento científico, a capacitação dos responsáveis pela sala de vacina, 
tornando profissionais conscientes de que estão cuidando de saúde, e da sobrevivência de milhões de cidadãos, e com isso promover um atendimento eficaz que atingirá às metas previstas e que irá ao encontro com o que preconiza as políticas de humanização do SUS, visando o ser humano em sua totalidade.

É pertinente ressaltar que apesar do aporte que o PNI ofertou para a saúde pública, ainda terá muitos desafios a enfrentar para continuar contribuindo com a manutenção da saúde da população brasileira, aprimorando cada vez mais as ações ofertadas pelo SUS.

\section{REFERÊNCIAS}

ABBAS, A. K.. Imunologia Celular e Molecular. Rio de Janeiro: Elsevier, 2012.

ABBAS, A. K.; LICHTMAN, A. H.. Imunologia Básica: Funções e Distúrbios do Sistema Imunológico. Rio de Janeiro: Elsevier, 2009.

ARAUJO, D.. Polarização epidemiológica no Brasil. Epidemiologia e Serviços de Saúde, Brasília, v.21, n.4, p.533538, 2012.

BAHIA. Superintendência de Vigilância e Proteção da Saúde. Manual de procedimento para vacinação. Salvador: DIVEP, 2011.

BLOCH, K. V.; LUIZ, R. R.; WERNECK, G. L.. Epidemiologia. 2 ed. São Paulo: Atheneu, 2009.

BOING, A. F.; SCHEIDT, P. P. R.. Centro de Referência de Imunobiológicos Especiais de Santa Catarina (CRIE-SC): uma descrição do perfil dos atendimentos no serviço. 2007.

BRASIL. Conselho Nacional de Secretários de Saúde. Atenção Primária e Promoção da Saúde. Brasília: CONASS, 2007.

BRASIL. Ministério da Saúde. Secretaria de Vigilância a Saúde. Saúde Brasil 2008: 20 anos de Sistema Único de Saúde (SUS) no Brasil. Brasília: Ministério da Saúde, 2009.

BRASIL. Ministério da Saúde. Secretaria de Vigilância em Saúde. Manual de Normas e Procedimentos para Vacinação. Brasília: Ministério da Saúde, 2014.

BRASIL. Ministério da Saúde. Secretaria de Vigilância em Saúde. Manual de rede de frio. Brasília: Ministério da Saúde, 2013.

BRASIL. Ministério da Saúde. Secretaria de Vigilância em Saúde. Manual dos centros de referência para imunobiológicos especiais. Brasília: Ministério da Saúde, 2006.

BRASIL. Ministério da Saúde. Secretaria de Vigilância em Saúde. Programa Nacional de Imunizações (PNI): 40 anos. Brasília: Ministério da Saúde, 2013.

BRASIL. Ministério da Saúde. Secretaria de Vigilância em Saúde.. Programa Nacional de Imunizações: 30 Anos. Brasília: Ministério da Saúde; 2003.

COICO, R.; SUNSHINE, G.. Imunologia. Rio de Janeiro: Guanabara Koogan, 2010.
CRESCÊNCIO, C. L.. Revolta da vacina: higiene e saúde como instrumentos políticos. Revista do Instituto de Ciências Humanas e da Informação, v.22, n.2, p.57-73, 2008.

DIOGO, M. A.. Educação permanente do agente comunitário de saúde: organização e planejamento na visita domiciliar. Volta Redonda, 2013.

FIGUEIREDO, S. S.. O Perfil da cobertura vacinal em crianças de uma comunidade, Rio de Janeiro, Brasil. SENPE. Anais. Campo Grande, 2011.

FRANÇA, I. S. X.. Cobertura vacinal e mortalidade infantil em Campina Grande, PB, Brasil. Rev. Bras. Enferm., v.62, n.2, 2009.

GONÇALVES, S. M. L.; MACHADO, M. F. A. S.. Opinião de um grupo de cuidadores sobre a imunização básica. Rev. RENE, Fortaleza, v.9, n.1, p.45-51, 2008.

GRAZIELE, L.. Imunização no Brasil: histórias e conceitos sob a ótica da enfermagem. Fortaleza, 2010.

HOMMA. Atualização em vacinas, imunizações e inovação tecnológica. 2010.

JÚNIOR, A. G. C.; COSTA, C. E. M.. Breve relato histórico das políticas públicas de saúde no Brasil. 2014.

JUNIOR, J. B. S.. 40 anos do Programa Nacional de Imunizações: uma conquista da Saúde Pública brasileira. Epidemiol. Serv. Saúde, v.22, n.1, 2013.

LEBRÃO, M. L.. O envelhecimento no Brasil: aspectos da transição demográfica e epidemiológica. Saúde Coletiva, v.4, n.17, p.135-140, 2007

LIMA, T. C. S.; MIOTO, R. C. T.. Procedimentos metodológicos na construção do conhecimento científico: a pesquisa bibliográfica. Rev. Katál., Florianópolis, v.10, n. esp., p.37-45, 2007.

MARCONI, M. A.; LAKATOS, E. M.. Metodologia Científica. 6 ed. São Paulo: Atlas, 2011.

MEDRONHO, R. A.. Epidemiologia. São Paulo: Atheneu, 2009.

MENICUCCI, T. M. G.. O Sistema Único de Saúde, 20 anos: balanço e perspectivas. Cad. Saúde Pública, Rio de Janeiro, v.25, n.7, p.1620-1625, 2009. 
MINAYO, M. C. S.. O desafio do conhecimento: pesquisa qualitativa em saúde. São Paulo: Hucitec, 1994.

MORAES, J. C.. Qual é a cobertura vacinal real?. Epidemiol. Serv. Saúde, v.12, n.3, 2003.

MORAES, J. C.; RIBEIRO, M. C. S.. Desigualdades sociais e cobertura vacinal: uso de inquéritos domiciliares. Rev. Bras. Epidemiol., v.11, n.1, 2008.

NETO, A. T. S.. Acolhimento na sala de vacina: a importância dos técnicos de enfermagem e agentes comunitários. 2013.

NÓBREGA, A. A.. Avaliação do Sistema de Informação do Programa de Imunizações (SI-API). Cad. Saúde Colet., Rio de Janeiro, v.18, n.1, p.145-153, 2010.

NUNES, E. M.. Vacinas: dúvidas mais frequentes. Belo Horizonte, 2013.

OLIVEIRA, C. M.; CRUZ. M. M.. Sistema de Vigilância em Saúde no Brasil: avanços e desafios. Saúde Debate, Rio de Janeiro, v.39, n.104, p.255-267, 2015.

OMRAM, A. R.. The epidemiologic transition: a theory of the epidemiology of population change. Bulletin of the World Health Organization, v.79, n.2, p.161-170, 2001.

PARSLOW, T. G.. Imunologia Médica. Rio de Janeiro: Guanabara Koogan, 2004.
PEREIRA, M. A. D.; BARBOSA, S. R. S.. O Cuidar de Enfermagem na Imunização: os mitos e verdade. Rev. Meio Amb. Saúde, v.2, n.1, p.76-88, 2007.

PEREIRA, M. G.. Epidemiologia: teoria e prática. Rio de Janeiro: Guanabara Koogan, 2014

PEREIRA, M. M. Q.. Atuação da equipe de enfermagem na sala de vacina e suas condições de funcionamento. In: CONGRESSO BRASILEIRO DE ENFERMAGEM, 61. Transformação Social e Sustentabilidade Ambiental, Fortaleza, 2009.

PINTO, L. L. S.. O programa nacional de imunizações para além do controle das doenças imunopreviníveis: uma história de 30anos. Revista Baiana de Saúde Pública, v.28, n.1, p.91-95, 2004.

PORTO, M. Y.. Uma revolta popular contra a vacinação. Cienc. Cult., v.55, n.1, 2003

SALLES, C. L. S.. Calendário de Vacinação. São Paulo, 2009.

SCHATZMAYR, H. G.. A varíola, uma antiga inimiga. Cad. Saúde Pública, Rio de Janeiro, v.17, n.6, p.1525-1530, 2001.

SILVA, T. A. S. M; CARREIRO, M. A.. Diagnóstico Situacional do Preparo e Administração de Imunobiológicos. Rev. Enferm., Rio de Janeiro, v.20, n.4, p.451-456, 2012. 